\title{
A PRECARIZAÇÃO DO CONTEMPORÂNEO OU O ESPETÁCULO DE TUDO ${ }^{1}$
}

\section{THE PRECARIZATION OF CONTEMPORANEOUS OR THE SHOW OF EVERYTHING}

\section{Rogério Lima*}

RESUMO: O objetivo deste artigo é contribuir para a discussão do conceito de cultura popular, refletindo sobre o processo de espetacularização em várias esferas da vida social e cultural e sobre as novas formas de ocupação do espaço público na contemporaneidade. PALAVRAS-CHAVE: Literatura, cultura contemporânea, vida cultural, precarização cultural, estética.

\begin{abstract}
This article aims to contribute to discussion of the concept of popular culture, reflecting on the process of spectacularization in various spheres of social and cultural life and the new forms of occupation of public space in contemporary society. KEYWOORDS: Literature, contemporary culture, cultural life, cultural impoverishment, aesthetic sensibility.
\end{abstract}

\footnotetext{
${ }^{1}$ Precariedade: termo adotado por Eugène Dupréel para designar esta característica dos valores segundo a qual qualquer que seja a sua "consistência", eles estão sempre sujeitos a serem violados, ignorados ou mesmo negados. "O valor é precário, pelo fato de apenas ter valor para um sujeito." Esquisse d'une philosophie des valeurs, p. 91. Ver sobre a consistência e a precariedade, 1a. parte, 3a. seção, cap. I. André Lalande. Vocabulário técnico e crítico da filosofia. São Paulo: Martins Fontes, 1999.

* Universidade de Brasília (UnB). Professor do Departamento de Teoria Literária e Literaturas, Instituto de Letras. Doutor em Semiologia pela Faculdade de Letras da Universidade Federal do Rio de Janeiro (UFRJ), expresidente da Anpoll, professor visitante da Fondation Maison des Sciences de l'Homme-Paris. Email: rlima@unb.br.
} 



\section{A PRECARIZAÇÃO DO CONTEMPORÂNEO OU O ESPETÁCULO DE TUDO}

O suor das costas que se apresenta

Como poesia trêmula de pai pra filho

E quando meu esforço quase não me convence

Privatizando a corrente sanguínea

E ela me persegue mais rápida

Que o nosso entendimento

Tão lenta quanto nosso perdão

Visto de cima, meu bairro é torto e glorioso

E se parece com o que nos transformamos em nossa fuga

Porque a sombra líquida, se te ganha

Te escurece os olhos

Faz a honestidade vulnerável

E aí fica fácil nos tornar quem odiamos

Sob o céu vermelho das traçantes

O mesmo passado que nos caça nos salvou

E pouco antes do meu futuro

Enfatizar em convulsão

Eu entendi que caminhar para o fim do túnel

é ouvir um silêncio sem permissão

Essa é minha busca e minha intenção

Porque lá em casa

Mesmo quando não tinha trabalho

Só tinha trabalhador ${ }^{2}$

2 YUCA; PACHECO; CEPPAS. “Sombra líquida”: In: Brasil: Sonny Music Entertainment, 2005. . F.UR.T.O. - Sangueaudiência. 
A minha primeira preocupação na preparação deste texto foi contribuir para a discussão do conceito de cultura popular, refletindo sobre a espetacularização em várias esferas da vida social e cultural e sobre as novas formas de ocupação do espaço público na contemporaneidade.

Neste momento, tenho trabalhado com o tema das fronteiras latino-americanas, mais especificamente as sul-americanas, e com as trocas intelectuais que são estabelecidas no contexto do Mercosul. Nesta pesquisa trabalhamos com uma noção de fronteira mais abrangente, que envolve uma gama de condições em que se confrontam, se encontram e se confundem temporalidades, ambientes, culturas, etnias, gêneros e estilos de vida distintos. Noções de fronteira que se ampliam para dar conta das diferenças, da compreensão do "outro", das identidades e dos estranhamentos nas bordas da América do Sul e do Mercosul, que modernamente passou a ser tratada como diversidade cultural.

No meu processo de pesquisa, tenho procurado integrar as diversas manifestações discursivas que visam construir a identidade latino-americana. Esses discursos emanam de diferentes áreas do conhecimento e da cultura: da cena eletrônica, economia, política, literatura, música, grafite, cinema, moda, fotografia, jornalismo, filosofia etc. Esse percurso é feito a partir de uma espécie de deriva cultural por cidades brasileiras e pelo continente, na área do Mercosul. Por esse motivo, tratarei de três temas recortados: o surgimento do espetáculo tecnológico que é o cinema, passando pela canção pop latino-americana até a forma de manifestação imprevisível e "anônima" que é o grafite.

\section{Bilac, João do Rio, Bandeira}

Gostaria de começar a discussão que proponho abordando três autores brasileiros que, de uma forma ou de outra, trataram, em seus textos, sobre a temática do espetáculo, ainda que não tenham utilizado esse termo, nem mesmo da forma como viria a ser utilizada por Guy Debord nos anos 1960.

Em setembro de 1907,o poeta Olavo Bilac publicou na revista Kosmos a crônica "Conferências e Cinematógrafo". Em sua crônica o poeta descreveu a exagerada proliferação de conferências no Rio de Janeiro da época. Bilac relata que somente no mês de fevereiro daquele ano tinham sido realizadas 48 conferências. Segundo ele, como toda cidade brasileira, vila ou freguesia tinha seus conferencistas, seria possível computar, à época, algo em torno de duas mil conferências que haviam ilustrado aquele se- 
tembro de 1907. Com o passar do tempo, essas conferências passaram de simples palestras "a seco", acompanhadas apenas de um copo de água, a verdadeiros eventos performáticos. Os oradores introduziram "variantes e novidades na moda".

Diz Bilac:

Tivemos conferências com música, conferências com música e canto, conferências com dança, conferências com projeções de lanterna mágica, conferências com ilustração a crayon. E parecia que nenhuma outra novidade poderia ser inventada - quando se espalhou uma comovedora notícia; o senhor X ia fazer uma conferência toda em verso, toda ritmada e toda rimada do princípio ao fim, sem uma linha de prosa (2005, p. 265).

Na mesma crônica, Bilac registra o surgimento de diversas salas de cinematógrafos ao longo da Avenida Rio Branco, da mesma forma como havia ocorrido com a Rua do Ouvidor tomada pelos fonógrafos:

[...] daqui a pouco, não poderemos dar um passo pela cidade, sem encontrar diante dos olhos um desses lençóis alvos em que as cenas da vida humana aparecem deformadas pelo tremor convulsivo da fita, e onde as figuras de homens e mulheres aparecem atacadas de delirium tremens ou de coréia, ${ }^{3}$ numa trepidação epilética... Como se a vida humana real já não fosse um espetáculo aborrecido e abominável e ainda tivéssemos a necessidade de vê-la infinitamente reproduzida pelas paredes! (2005, p. 267).

No prefácio do seu livro Cinematógrapho, o escritor e jornalista João do Rio ressaltou que o cinematógrafo tinha como qualidade ser um "excelente documento com a excelente qualidade a mais de não obrigar a pensar, senão quando o cavalheiro teima mesmo em querer ter idéias" (1909). Essa parece ser hoje a qualidade imposta ao cinema pelos grandes estúdios norte-americanos produtores cinematográficos.

A crônica "A revolução dos filmes", publicada em Os dias passam, de 1912, registra a transformação dos costumes trazida pelo cinema ao sécu-

3 Neuro, segundo Novo Dicionário Aurélio: distúrbio encefálico caracterizado por movimentos musculares anormais e espontâneos, sem propósito, irregulares, rápidos e transitórios, sugerindo uma dança. 
lo XX. Em uma conversa com um "velho frequentador de festas populares", João do Rio indaga sobre onde foi parar a Semana Santa, já que as igrejas estão vazias. O seu interlocutor responde que está nos cinematógrafos. Diz ele: “Vá ver. Os 'filmes' de arte realizaram uma completa transformação nos costumes. [...] O cinematógrafo acaba de fazer a grande revolução. Venha vê-los é Cristo em espetáculo" (2005, p. 217-218).

Em "A crítica e o cinema", publicada na revista Para Todos, em 7 de julho de 1928, Manuel Bandeira comenta o empenho do crítico francês Léon Moussinac em publicar no diário parisiense L'Humanité uma crítica isenta sobre todos os filmes e sua dedicação "por incutir no público o gosto pela verdadeira arte da tela, tão abastardada pelo contágio das artes contíguas, especialmente o romance e o teatro" (2008, p. 30).

Bandeira ressalta os esforços de Moussinac em afirmar o cinema como arte autônoma e de qualidade que não deveria ser contaminada por aproximações espúrias com a literatura de apelo fácil ao público, cujo único interesse era ganhar dinheiro. Bandeira alinha-se na defesa do cinema como meio de expressão contra o cinema mercadoria, "açambarcada pelos formidáveis trusts americano-europeus que impõem, mercê de retumbantes reclames, o sucesso de fitas absolutamente idiotas, onde o que há de melhor são as pompas dos cenários clinquant, ${ }^{4}$ o luxo espetaculoso e a lascívia dos astros" (2008, p. 303).

O comentário de Bandeira nos remete à discussão proposta pelo cineasta alemão Wim Wenders em seu filme Sob o céu de Lisboa (1994) sobre a validade de um cinema que procura vender algum tipo de produto ao espectador a cada sequência da sua trama. Wenders critica o cinema que perdeu a sua pureza. Este argumento é utilizado pelo personagem Friedrich Monroe (Patrick Bauchau), diretor de cinema, na sua conversa com engenheiro de som Phillip Winter (Rüdiger Vogler), que viajara até Lisboa para ajudá-lo na finalização do filme que está rodando na cidade e cuja produção se encontra paralisada, por conta de uma crise de criação que se abate sobre o diretor (LIMA, 2000, p. 173).

Se prestarmos atenção aos filmes de Wenders poderemos constatar que sempre há um aparelho de TV ligado e não há nada sendo transmitido. Tudo o que vemos é o chamado efeito poltergeist de um canal de TV fora do ar. O argumento de Wenders para a aparição dos aparelhos de TV dessa forma

\footnotetext{
4 Em francês, "falso brilho".
} 
em seus filmes é que o discurso televisivo é um discurso raso, onde não há nada para ser dito, o que existe na TV é apenas um discurso de aparências, um ornamento para as massas. Utilizo aqui o termo cunhado por Siegfried Kracauer (2009), que, de certa forma, antecipa o conceito de espetáculo de Guy Debord (1997).

\section{Aterciopelados, F.UR.T.O}

Efetuando um corte e cruzando a fronteira da canção pop latino-americana, é possível encontrarmos, no mesmo registro que Wim Wenders faz no cinema contemporâneo, a crítica ao espetáculo do vazio e às sensibilidades construídas pela mídia. Diversos grupos de rock latino-americanos têm abordado, nas letras das suas composições, a temática que trata das diversas formas de construção da desigualdade, modelagem do imaginário e gosto estético das populações urbanas que já não vivem sem a televisão desde os anos 1950.

A estetização dos corpos e a valorização excessiva da aparência física, construída a partir de conceitos midiáticos de beleza, entram constantemente em choque com a realidade biométrica e antropológico-cultural dos indivíduos. Esse conflito é fator gerador de muita angústia, principalmente no público feminino, alvo preferido dos apelos da indústria da moda e das revistas sobre celebridades. A todo instante, somos atingidos por enorme gama de informações e estímulos que elegem padrões comportamentais e de estética corporal que devem ser seguidos, cujo objetivo principal é criar também um padrão de aceitação sociocultural, inserindo o corpo e a subjetividade em uma espécie de espetáculo.

Aparências e espetacularização do corpo são o tema da canção El estuche, do grupo colombiano Los Aterciopelados ${ }^{5}$ :

No es un mandamiento ser la diva del momento (wow)

Para que trabajar por un cuerpo escultural,

¿A caso deseas sentir en ti todos los ojos?

¿Y desencadenar silbidos al pasar...?

\footnotetext{
5 Aterciopelados é um grupo colombiano de rock alternativo, que foi criado em 1990 com o nome "Delia y los Aminoácidos", tendo mudado para Aterciopelados em 1992. O grupo é formado por Andrea Echeverri (vocalista) e Hector Buitrago (baixo). Foram indicados pela Time como uma das melhores bandas do mundo. Acessado em: <http:pt.wikipedia. orgwikiAterciopelados>. Acesso em: 20 mar. 2011.
} 
Mira la esencia, no las apariencias (x2)

El cuerpo es solo un estuche y los ojos la ventana,

De nuestra alma aprisionada (oye)

Mira la esencia, no las apariencias (x1)

Que todo entra por los ojos dicen lo superficiales,

Lo que hay adentro es lo que vale

Siento en el aire, un aroma espiritual

Mensajeros halados intentando aterrizar

Si abres el estuche lo que debes encontrar

Es una joya que te deslumbrara (hay pero)

Mira la esencia, no las apariencias (x2)

90-60-90, suman doscientos cuarenta,

Cifras que no hay que tener en cuenta (oye)

Mira la esencia, no las apariencias (x1)

No te dejes medir,

no te dejes confundir ¡Agúzate! Hazte valer

¡Agúzate! Hazte valer (x5)

Nesta canção, Los Aterciopelados ironizam o discurso do senso comum sobre a valorização midiática do corpo e o discurso pseudo-filosófico-espiritual de valorização do ser.

Na letra da canção "Ego City", do grupo carioca F.UR.T.O, Frente Urbana de Trabalhos Organizados, é possível lermos a crítica ao mundo do ornamento, do consumo, do poder, do sexo, da corrupção.

Carros à prova de bala,

com vidros à prova de gente

Cor fumê da indiferença

E vão lambendo os cartões de crédito

Comprando de quase tudo;

do orgulho à cocaína

de dólares a meninas

Passando em frente à réplica da Estátua da Liberdade

que nos prende ao consumo siliconizado

E farpado urgente que diz: 
Bem-vindo a Ego City

Lutadores sem filosofia, crianças sem esquinas

Realidade da portaria, mas só se for pela porta dos fundos

De frente pro mar, de costas pro mundo Perderam o governo, mas ainda seguram os trunfos

Quando cair, delete o meu nome dos seus computadores

Se você insistir, o meu descanso será seu pesadelo

Lembre-se do mistério de PC, dono do Avião Negro

Porque o terno e o uniforme ainda

são os disfarces mais usados pelo crime

Tráfico de influência, tráfico de vaidade, tráfico pra ocupar

melhor lugar na corte

Bem-vindo a Ego City

Na canção "Flores nas encostas de cimento", o sentimento e a noção de precariedade também se encontram presentes de forma intensa. O Eu lírico da canção luta contra o apagamento cultural a partir da valorização que faz do Samba como gênero musical popular importante para a expressão dos seus sentimentos.

A infiltração no teto fazia marcas

Que eu de tanto olhar via as faces mais lindas

Para clarear o meu tormento

Como flores nas encostas do cimento

Antes que o samba vire só um ruído de fundo

Eu vou tocar mais alto para ouvir meu coração

Porque não existe enredo

Do inferno que me tire a emoção 
E se as luzes nos roubassem as estrelas

E nosso brilho só nos mostrasse

A silhueta do que poderíamos ser

Eu já estive pior e agora posso entender

Para clarear o meu tormento

Como flores nas encostas do cimento

Antes que o samba vire só um ruído de fundo

Eu vou tocar mais alto para ouvir meu coração

Porque não existe enredo

Do inferno que me tire a emoção

A temática da precariedade política, social, ambiental e econômica pode ser observada também na canção "Dia Paranormal”, de Los Aterciopelados.

Hoy se doblan cucharas, se derrite el glaciar y

se arreglan las leyes para politiquear,

se despierta el casquete polar,

abrimos hoyos al ozono espacial,

al Edén lo convierten en paraíso fiscal,

y se siembra la tierra con mina personal,

y el último bosque tropical,

lo compró la multinacional.

Hoy que día es, día paranormal, así es hoy,

ojalá que acabe, hoy que día es,

día paranormal, hey hey ho, quiera Dios que acabe

Hoy se extingue el chigüiro, en completa impunidad

y medimos el tiempo fuera del ciclo lunar,

los canales de televisión,

nos construyen nuestra humilde opinión,

se desocupan los ríos, para el agua embotellar,

y se espantan las gentes de su

casa legal, cortinas de humo ocultan la verdad,

y la memoria nos quieren borrar. 


\section{Octávio Paz e o herói contemporâneo}

No estudo em que aborda a questão relativa à ambiguidade do romance, em Signos em Rotação, Octávio Paz trata da função mais imediata da poesia, que ele considera também como função histórica, e essa consiste:

[...] na consagração ou transmutação de um instante, pessoal ou coletivo, em arquétipo. Nesse sentido a palavra poética funda os povos. Sem épica não há sociedade possível, porque não existe sociedade sem heróis em que reconhecer-se. Jacob Buckhardt foi um dos primeiros a advertir que a épica da sociedade moderna é o romance. Mas deteve-se nessa afirmação e não penetrou na contradição que encerra o chamar-se épico a um gênero ambíguo, no qual cabem desde a confissão e a autobiografia até o ensaio filosófico" (1976, p. 68).

“O herói épico é um arquétipo, um modelo." Aqui eu pergunto: os heróis dos nossos tempos serão personagens de filmes comerciais ou de video games?

Em seus depoimentos nos filmes documentários sobre as guerras do Afeganistão e do Iraque, os jovens soldados americanos, que participam dessas guerras, relatam que, quando estão em ação em uma missão, visualizam os alvos a serem atingidos por meio das telas dos seus blindados. Embalados pela trilha sonora dos seus video games favoritos disparam contra aqueles que foram modelados pelos interesses geopolíticos como o inimigo que deve ser eliminado. A utilização de tecnologias altamente precisas e mortíferas, muito parecidas com as de um jogo eletrônico de guerra, faz com que a ação militar assuma o "caráter lúdico" de jogo onde o Bem, na segurança espetacular do blindado tecnologicamente desenvolvido, luta para salvar o Ocidente do Mal.

Porém, ao primeiro revide imposto com sucesso pelo inimigo e diante da visão do sangue dos companheiros com seus membros dilacerados, a percepção infantil da guerra como um jogo eletrônico desaparece. A visão lúdica da guerra dá lugar ao desespero, à incredulidade e à consciência repentina da fragilidade humana. Creio que, olhando diretamente para a face do entretenimento, não devemos esquecer que a indústria de jogos eletrônicos tornou-se poderosíssima. Ela não está no mercado para perder tempo, espaço de comercialização ou dinheiro. Creio que um dos seus trunfos para garantir a sua hegemonia mercadológica é a espetacularização da violência como grande elemento, e talvez o "único", de atração narrativa dos jogos. 
É importante ressaltarmos também que os jogos eletrônicos ocupam grande espaço de tempo no cotidiano dos seus usuários. Pois, diariamente, uma grande quantidade de horas é dedicada aos video games. Querendo ou não, esses jogos passaram a fazer parte da formação intelectual e cultural dos seus jogadores. É recorrente a realização de estudos multidisciplinares que visam medir o grau de sociabilidade e de comunicabilidade a que os jogadores de video games estão submetidos. As conclusões a que se tem chegado é que os jogadores, cada vez mais jovens, tendem a entrar em um regime de comunicabilidade mínima, por conta do tempo dedicado aos games. Isso significa dizer que há uma diminuição da sociabilidade exercitada em um meio quente, ou seja, o número de horas dedicadas à convivialidade no mundo real, onde as pessoas se encontram e podem perceber as alterações faciais e de humor do seu interlocutor, tende a sofrer redução bastante significativa.

Ao tratar sobre o fenômeno da incomunicabilidade, Octávio Paz aponta para o mundo da técnica: "Se o mundo como imagem se desvanece, uma nova realidade cobre toda a Terra. A técnica é uma realidade tão poderosamente real - visível, palpável, audível, ubíqua - que a verdadeira realidade deixou de ser natural ou sobrenatural: a indústria é nossa paisagem, nosso céu e nosso inferno". Em outro momento, Paz escreve: "A técnica não é nem uma imagem nem uma visão do mundo: não é uma imagem porque não tem por objeto representar ou reproduzir a realidade; não é uma visão porque não concebe o mundo como figura, e sim como algo mais ou menos maleável para a vontade humana" (1976, p.103).

\section{Transgressão e formas anônimas de manifestação}

Em Paris, entre setembro e dezembro de 2008, enquanto preparava um seminário para apresentar na Fondation Maison des Sciences de l'Homme-Paris, passei a observar os cartazes nas paredes do metrô, os muros das ruas, as vitrines das lojas. Caminhando pela cidade, tive a atenção despertada para algumas inscrições que capturaram minha sensibilidade de forma imediata. Na vitrine de uma loja de molduras, na rua de l'Arbaète, $5^{\mathrm{e}}$ arrondissement, me deparei com a seguinte inscrição: "É melhor reinar no inferno do que servir no paraíso", John Milton. Abaixo dessa inscrição havia um pequeno exemplar de $O$ paraíso perdido, editado pela editora francesa Folio. Alguns metros adiante, no coração da rua Mouffetard, na parede de um café-restaurante, havia a seguinte inscrição grafitada: "A poesia é 
o esporte do extremo". O texto era assinado por Miss. Tic. ${ }^{6} \mathrm{Na}$ estação de Jussieu, sobre o cartaz que anunciava o show de uma dupla de cantores pop, composta por um homem negro e outro branco, alguém escreveu, na manhã da eleição do presidente Barack Obama, sobre a face do homem branco: "Voto negro"; e sobre a figura do cantor negro: "Poder branco". Em um dos corredores da estação Odeon do metrô, sobre um grande cartaz que convidava os passantes a visitarem a Martinica, haviam escrito: "Papéis para todos", denunciando a condição de precariedade dos imigrantes que se encontram em condições ilegais na França.

Os muros e as paredes da cidade, já há algum tempo, assumiram o lugar-suporte de textos que possuem características diversas que vão do texto gráfico calcado no alfabeto ao texto pictórico ou mesmo apresentando uma combinação dos dois. O grafite, arte eminentemente urbana, instaura uma nova poética visual das ruas, quebrando a monotonia do olhar urbano. Arte engajada, cosmopolita, que se transformou em um modo de vida, conquista diariamente o seu espaço à força. O grafite se instaura, se impõe e se mostra a partir de uma invasão territorial. A noção de território passa a ser fundamental nessa ação e intervenção artística, pois o grafiteiro invade e ocupa o território urbano com a sua arte de guerrilha.

O suporte do grafite é todo o espaço que o grafite possa ocupar, seja ele uma parede, um muro, um trem, um carro, uma ponte de ferro ou de concreto, não importa. Assim como não parece importar o lugar ou território onde o grafite é exposto, pois muitas vezes é possível encontrá-lo em lugares inusitados, de pouca circulação de pessoas e de iluminação precária, oferecendo-se à surpresa dos olhares distraídos ou embotados dos habitantes das metrópoles.

O grafite como elemento de ação de resistência e luta contra a precariedade social é o tema da canção "Monstro Invisível”, do grupo O Rappa (2009).

Monstro invisível que comanda a horda

Arrasando tudo o que é de praxe

Eu tô laje acima, no cerol que traz a vida pra baixo

\footnotetext{
6 Miss. Tic é poeta e artista plástica. Grande figura da street art que faz das ruas parisienses a sua mais bela galeria. Desde 1985, ela grafita sobre os muros de Paris bilhetes bem humorados e muitas vezes corrosivos, são retratos de mulheres legendados por frases pertinentes e "impertinentes" que instigam os transeuntes a refletirem sobre o cotidiano e sobre o tempo que passa.
} 
Brilhante ideia de uma cabeça nervosa

Grafitando um outro muro de raiva

Eles já sabiam, mas deixaram a sina guiar a sorte

Vejo a minha história com a sua comungar

Vejo a história, ela comungar

Vejo a minha história com a sua comungar

Vejo a história, ela comungar

Vejo a minha história com a sua comungar

Vejo a história, ela comungar

Vejo a minha história com a sua comungar

Poço lado e sujo, cria do descaso

Alimentando folhas em branco e preto

Outra epidemia desanima quem convive com medo

Botões e atalhos amplificam a distância

$E$ a preguiça de estar lado a lado veste a armadura

Esse é o poder solitário

Vejo a minha história com a sua comungar

Vejo a história, ela comungar

Vejo a minha história com a sua comungar

Vejo a história, ela comunga

Vejo a minha história com a sua comungar

Vejo a história, ela comungar

Vejo a minha história com a sua comungar

Monstro invisível que comanda a horda

Arrasando tudo o que é de praxe

Eu tô laje acima, no cerol que trás a vida pra baixo

Brilhante ideia de uma cabeça nervosa

Grafitando um outro muro de raiva

Eles já sabiam, mas deixaram a sina guiar a sorte

Vejo a minha história com a sua comungar

Vejo a história, ela comungar

Vejo a minha história com a sua comungar

Vejo a história, ela comungar (2x)

Comungar, comungar, comungar, comungar, comungar

Vejo a história, ela comungar

Vejo a minha história com a sua comungar

Vejo a história, ela comungar 
Vejo a minha história com a sua comungar

Vejo a história ela comungar

Comungar, comungar, comungar, comungar, ei $(2 \mathrm{x})$

Essa é uma canção interessante, pois agrega elementos na sua construção que vão do ódio ao medo, passando pelo descaso político e social, para desaguar na resistência do grafite. Esse tipo de manifestação artística cria identidade, comunhão de ideias, de atitudes, e se realiza, primordialmente, em território público, como uma ação de guerrilha que requer planejamento, estratégia, trabalho e muito suor.

A expressão do grafite nas ruas é uma das formas de representação da retomada da transgressão. Podemos entendê-lo também como forma de manifestação contra a representação do dinheiro como valor supremo, contra a ideia conformista de que já não há mais contra o que transgredir.

Podemos afirmar que o espírito da transgressão existe e exterioriza sua indignação fazendo uso de formas anônimas ou não anônimas de manifestação como os grafites que podemos ver sobre os muros das metrópoles e sobre toda a superfície utilizável, inscritível ou poderíamos dizer: inscrevível. Como exemplo, posso citar uma inscrição em um prédio junto à Plaza de Mayo, em Buenos Aires: "Os lápis seguem escrevendo", além de diversas outras inscrições que tomam como objeto o poder sobre o corpo, a política, a economia etc.

Essas manifestações do grafite nos fazem lembrar o poema "Nova Poética", de Manuel Bandeira:

Vou lançar a teoria do poeta sórdido.

Poeta sórdido:

Aquele em cuja poesia há a marca suja da vida.

Vai um sujeito,

Sai um sujeito de casa com a roupa de brim branco muito bem [engomada, e na primeira esquina passa um [caminhão, salpica-lhe o paletó ou a calça [de uma nódoa de lama:

É a vida.

O poema deve ser como uma nódoa no brim:

Fazer o leitor satisfeito de si dar o desespero. 
Sei que a poesia é também orvalho.

Mas este fica para as menininhas, as estrelas alfas, as virgens cem

[por cento e as amadas que envelheceram

[sem maldade (1974, p. 287).

É possível dizermos que o grafite é a "marca suja" da poética do espaço urbano. É a mancha que irrompe em espaços inusitados criando a necessidade de entendimento e de significação em quem o absorve como informação poético-visual, exigindo a decifração da sua mensagem. O grafite, como linguagem artística urbana, força o rompimento da fronteira invisível da acomodação e do embotamento estético imposto pelo barateamento cotidiano das sensibilidades urbanas.

A ideia de fronteira sempre nos remete ao conceito de espaço e de limites a serem transpostos ou não. Lembro aqui de um antigo seriado televisivo norte-americano, Jornada nas estrelas, que iniciava sempre com a seguinte frase: "O espaço, a fronteira final, onde nenhum homem jamais esteve". Nesse caso, a fronteira é algo distante que "aguarda" para ser conquistada.

Contemporaneamente, a fronteira é lugar de grandes tensões, de vigília constante, que precisa ser controlada diuturnamente a fim de inibir o trânsito de indesejados, sejam eles pessoas, sejam mercadorias, daqueles que buscam trabalho, manifestar sua arte, melhores condições de vida etc.

As nações desenvolvidas sentem que é preciso construir muros e cercas para suprimir o trânsito de pessoas que buscam sonhos de vida melhor. No contexto cultural, é grande a produção latino-americana, e de grande

7 Jornada nas Estrelas (Star Trek) é uma marca de ficção científica estadunidense criada pelo roteirista e produtor Gene Roddenberry na década de 1960 e, posteriormente, desenvolvida por ele e por outros produtores. O universo ficcional de Star Trek é o cenário de seis séries televisivas, onze filmes para o cinema, centenas de livros - romances, banda desenhada, desenho animado, enciclopédias, dicionários, "manuais técnicos" e mesmo textos científicos e filosóficos -, dúzias de jogos para computador e consoles e um parque temático em Las Vegas. No "universo" de Star Trek, a humanidade desenvolveu a tecnologia das viagens espaciais mais rápidas que a luz, após uma fase pós-apocalíptica em meados do século XXI. Posteriormente, os seres humanos uniram-se a outras espécies da galáxia para formar a Federação dos Planetas Unidos. Resultado da intervenção alienígena e do progresso científico, a humanidade, na altura do século XXIII, já teria superado muitos de seus defeitos e vicissitudes, teria erradicado doenças e a pobreza e se dedicaria a explorar novos mundos. As histórias de Star Trek costumam descrever as aventuras de seres humanos e alienígenas que servem na Frota Estelar da Federação.

Disponível em: <http:pt.wikipedia.orgwikiStar_Trek>. Acesso em: 20 jan. 2010. 
diversidade, que aborda o desejo do homem pelo acesso ao trabalho, à cultura, ao respeito enquanto ser humano. Podemos citar aqui as canções: "Clandestino", do francês Manu Chao, "Desterro", do brasileiro Marcelo Yuca, e "Los Condenaditos" e "Matador", dos argentinos Los Fabulosos Cadillacs.

Essas canções têm como tema os modos de vida no mundo ocidental e, especificamente, na América Latina e colocam em questão o discurso universalista euro-norte-americano que a superestrutura capitalista constrói para garantir a dominação ou a tutela sobre povos considerados atrasados. Sob esses argumentos universalistas "O império das potências sobre o globo seria inevitável e às outras nações não haveria alternativa a não ser submeter-se ao jugo dos que dominam o mundo" (MONIZ BANDEIRA, 2007). Essas canções, assim como as canções interpretadas pela cantora argentina Mercedes Sosa ou pela chilena Violeta Parra, estão inseridas no processo de construção da identidade latino-americana.

Gostaria de evocar aqui o cubano Alejo Carpentier que em seu discurso "Consciência e identidade da América", pronunciado na Aula Magna da Universidade Central da Venezuela, em 15 de maio de 1975, disse:

[...] Podemos ser vítima de um mesmo adversário. Por isso a história de nossa América deve ser estudada como uma grande unidade, como a de um conjunto de células indissociáveis umas das outras, para conseguir entender realmente $o$ que somos, quem somos e que papel devemos desempenhar na realidade que nos circunda e dá um sentido aos nossos destinos. José Martí dizia, em 1893, dois anos antes de sua morte: "Nem o livro europeu, nem o livro ianque nos darão a chave do enigma hispano-americano". Para mais adiante completar: "Devemos ser ao mesmo tempo homens de nosso tempo e de nosso povo; mas havemos de ser principalmente homens de nosso povo". E eu acrescentaria que, para entender esse povo - esses povos -, é preciso conhecer sua história a fundo (2005, p. 163).

O objetivo da citação do trecho do discurso de Carpentier no final deste texto é ressaltar a importância de estarmos atentos às manobras do espetáculo para capturar a nossa sensibilidade e a nossa imaginação.

Outro latino-americano, o poeta e ensaísta paraguaio Rubén Bareiro Saguier, chama atenção para uma questão que está sempre a nos rodear: "Dada a diversidade de componentes, um problema latino-americano essencial foi, 
e continua sendo, encontrar a sua identidade cultural, situação que a literatura reflete ao procurar apropriar-se de uma linguagem e concretizar um conteúdo num idioma em certa medida emprestado, e dentro de um contexto político não unificado" (1972, p. 5).

Devemos estar atentos à preservação cultural dos nossos povos e do patrimônio imaterial das nossas culturas. Pois, ainda que se fale em rompimento de fronteiras nacionais ou identidades nacionais para facilitar o trânsito de mercadorias, é a partir de identidades construídas e imaginadas por nossas comunidades que modelamos a riqueza da nossa vida cotidiana e somos capazes de construir a nossa percepção das diversas formas de assédio que sofremos.

Esses assédios têm características muito dissimuladas e sutis. Quase sempre estão embalados em uma atmosfera hipermoderna e modulados por um discurso sedutor e impositivo, que repete, insistentemente, que devemos abandonar maneiras particulares e autônomas de ver o mundo, consideradas ultrapassadas. Para o discurso economicamente e culturalmente hegemônico, ser moderno e contemporâneo é apagar as identidades, o nacional e aderir ao grande fluxo global dos negócios. Nesse cenário, compositores, grafiteiros, escritores, cineastas, professores etc. têm importante papel a desempenhar na construção da consciência que sabe identificar o perigo trazido pelo monstro invisível que nos ronda.

Com o auxílio do verso de Marcelo Yuca, eu diria: “[...] que sempre é hora de sermos mais inteiros/ Todos debaixo do mesmo sombreiro".

\section{Referências Bibliográficas}

ATERCIOPELADOS. Disponível em: <http:www.aterciopelados.com>. Acesso em: 20 mar. 2011.

BANDEIRA, L. A. Moniz. Apresentação. In: WALLERSTEIN, Immanuel. O Universalismo Europeu: a retórica do poder. Trad. Beatriz Medina. São Paulo: Boitempo, 2007.

BANDEIRA, Manuel. Poesia e prosa. 3 ed. Rio de Janeiro: José Aguilar Editora, 1974.

8 YUCA. “Todos debaixo do mesmo sombrero". In: F.UR.T.O - Sangueaudiência. Brasil:

Sony Music Entertainment, 2005. 
. Crônicas Inéditas I. São Paulo: Cosac Naify, 2008.

BILAC, Olavo. Crônicas. São Paulo: Global, 2005. (Coleção Melhores Crônicas, dirigida por Edla van Steen).

CARPENTIER, Alejo. Identidade americana. In: Visões da América. São Paulo: Martins Fontes, 2005.

DEBORD, Guy. A sociedade do espetáculo. Trad. Estela dos Santos Abreu. São Paulo: Contraponto,1997.

KRACAUER, Siegfried. O ornamento da massa. Trad. Carlos E. J. Machado, Marlene Holzhausen. São Paulo: Cosac Naify, 2009.

LALANDE, André. Vocabulário técnico e crítico da filosofia. São Paulo: Martins Fontes, 1999.

LIMA, Rogério. A permanência das imagens e os fragmentos da esquina: Wim Wenders e Paul Auster e as formas de imaginação da cidade. In: ; FERNANDES, R. O imaginário da cidade. Brasília: Editora UnB; São Paulo: Imprensa Oficial, 2000.

MISS. TIC. Je prète à rire mais je donne à penser. Paris: Edition Grasset \& Fasquelle, 2008.

O RAPPA. Disponível em: <http:www.orappa.com.brorappaorappa.html>. Acesso em: 20 jan. 2010.

PAZ, Octávio. Signos em rotação. São Paulo: Perspectiva, 1976.

RIO, João do. Cinematógrapho. Porto: Chadron, 1909.

. Crônicas. Org. Edmundo Bouças; Fred Góes. São Paulo:

Global, 2005. (Coleção Melhores Crônicas, dirigida por Edla van Steen).

SAGUIER, R. Bareiro. Encontro de Culturas. In: MORENO, C. Fernandez (Org.). América Latina em sua literatura. São Paulo: Editora Perspectiva, 1972.

WALLERSTEIN, Immanuel. O Universalismo Europeu: a retórica do poder. Trad. Beatriz Medina. São Paulo: Boitempo, 2007.

YUCA, Marcelo. Todos debaixo do mesmo sombrero. In: YUCA. F.UR.T.O - Sangueaudiência. Brasil: Sony Music Entertainment, 2005. 


\section{Discografia}

YUKA, M. F.UR.T.O - Sangueaudiência. Brasil: Sorny Music Entertainment, 2005.

O RAPPA. 7 vezes. Brasil: Warner Music Brasil, 2008.

\section{Filmografia}

WENDERS, Wim. Sob o céu de Lisboa. Distribuidora: Universal. 1994. 